\title{
A Case of Middle Ear Implantation Using the Vibrant Soundbridge in a Patient with Bilateral Mixed Hearing Loss
}

\author{
Yong Gook Shin ${ }^{1}$, Ja Won $\mathrm{Gu}^{1}$, Jin Wook Kang ${ }^{1}$, and Mee Hyun Song ${ }^{2}$ \\ ${ }^{1}$ Department of Otorhinolaryngology-Head and Neck Surgery, Myongji Hospital, Goyang; and \\ ${ }^{2}$ Department of Otorhinolaryngology-Head and Neck Surgery, Myongji Hospital, Hanyang University College of Medicine, Goyang, Korea
}

\section{양측 혼합성 난청 환자에서 Vibrant Soundbridge를 이용하여 시행한 인공중이이식술 1예}

신용국 ${ }^{1} \cdot$ 구자원 $^{1} \cdot$ 강진욱 $^{1} \cdot$ 송미현 ${ }^{2}$

명지병원 이비인후과, ${ }^{1}$ 한양대학교 의과대학 명지병원 이비인후과 ${ }^{2}$

\author{
Received June 4, 2018 \\ Revised August 9, 2018 \\ Accepted August 31, 2018 \\ Address for correspondence \\ Mee Hyun Song, MD, PhD \\ Department of Otorhinolaryngology- \\ Head and Neck Surgery, \\ Myongji Hospital, \\ Hanyang University \\ College of Medicine, 55 Hwasu-ro, \\ 14beon-gil, Deogyang-gu, \\ Goyang 10475, Korea \\ Tel $+82-31-810-6360$ \\ Fax $+82-31-810-6357$ \\ E-mail meehyun924@hanmail.net
}

It is challenging to achieve sufficient hearing gain in patients with mixed hearing loss. In chronic middle ear diseases, conventional passive reconstructive surgeries often result in suboptimal hearing gain and additional hearing aids may have limitations due to insufficient sound amplification, occlusion effect, acoustic feedback, and skin irritation. Middle ear implantation (MEI) using Vibrant Soundbridge (VSB) is another option for auditory rehabilitation in mixed hearing loss as well as sensorineural hearing loss. The floating mass transducer of VSB can be placed on various middle ear structures either directly or using different types of couplers in order to deliver vibratory mechanical energy to the cochlea. We report a patient who presented with bilateral mixed hearing loss due to chronic otitis media and had limitations using conventional hearing aids in the worse hearing ear. The patient was successfully treated with MEI using the Bell coupler together with middle ear surgery in a single step. Korean J Otorhinolaryngol-Head Neck Surg 2018;61(12):705-9

Key Words Bell-coupler · Middle ear implant · Mixed hearing loss · Vibrant Soundbridge · Vibroplasty.

\section{Introduction}

Achieving a satisfactory hearing improvement in patients with mixed hearing loss can be challenging. In cases of chronic middle ear diseases, conventional ossicular reconstructive surgeries often result in suboptimal hearing gain, and the failure rates have been reported to increase over time reaching up to $50-60 \%$. $^{1)}$ Due to the remaining sensorineural component of hearing loss after the surgery in patients with mixed hearing loss, additional use of hearing aids is

This is an Open Access article distributed under the terms of the Creative Commons Attribution Non-Commercial License (https://creativecommons.org/licenses/by-nc/4.0) which permits unrestricted non-commercial use, distribution, and reproduction in any medium, provided the original work is properly cited. frequently required, which can be hindered by the widened external auditory canal or chronic otitis externa. Furthermore, if there is a large air-bone gap remaining after passive reconstruction in mixed hearing loss, conventional hearing aids may be limited in providing sufficient functional gain. An active middle ear implant using the Vibrant Soundbridge (VSB; MED-EL, Innsbruck, Austria) is another option for auditory rehabilitation in patients with mixed hearing loss who failed with conventional modalities. ${ }^{2)}$ The floating mass transducer (FMT) of the VSB can be placed on various middle ear structures either directly or using different types of couplers in order to deliver vibratory mechanical energy to the cochlea. ${ }^{3)}$ 

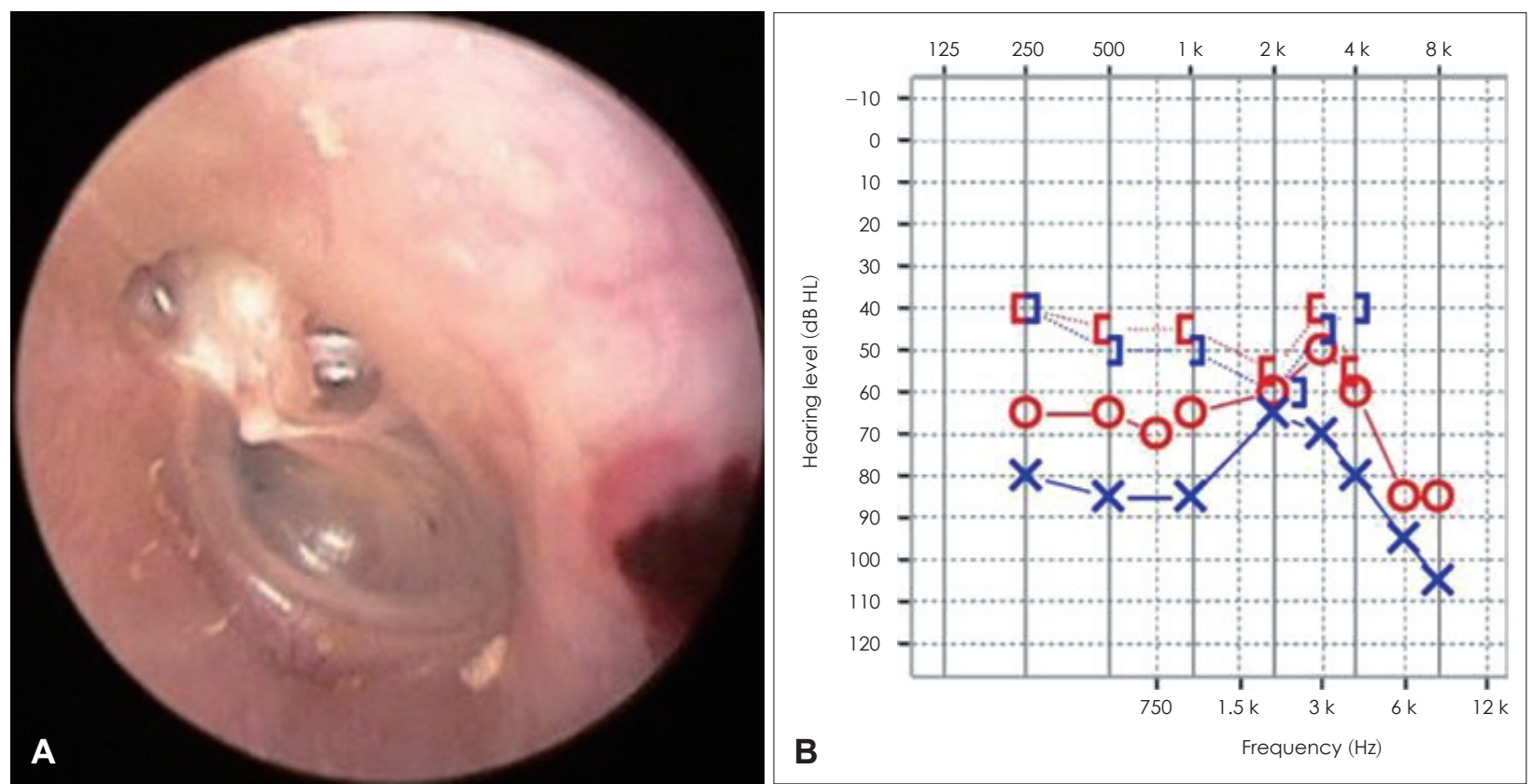

Fig. 1. Endoscopic view of left tympanic membrane. Attic destruction and retraction of drum were identified on the left side (A). Preoperative pure tone audiometry. Pure tone audiogram showed mixed hearing loss on both sides with air-conduction pure tone average of $60 \mathrm{~dB}$ $\mathrm{HL}$ on the right side and $76 \mathrm{~dB} \mathrm{HL}$ on the left side (B). O: right air-conduction unmasked, X: left air-conduction unmasked, [: right boneconduction masked, ]: left bone-conduction masked.

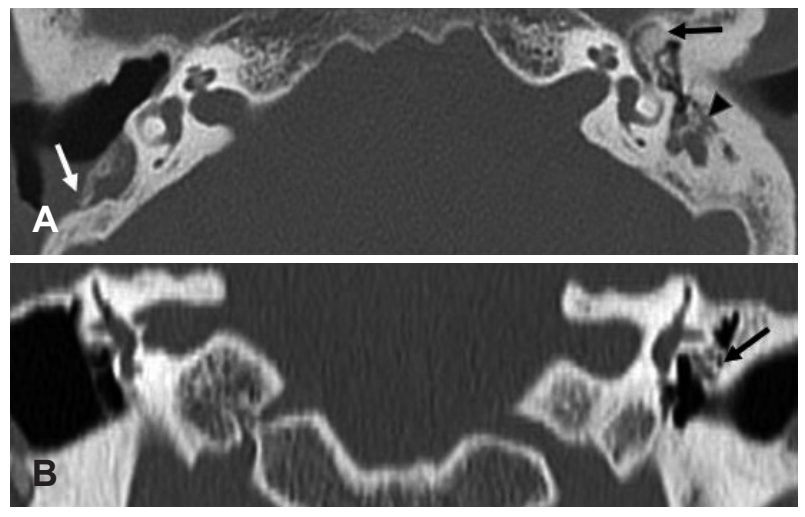

Fig. 2. Temporal bone CT. An axial image demonstrates drilled temporal bone due to previous canal wall down mastoidectomy on the right side. New bone formation in epitympanic area and soft tissue density in antrum were identified on the left side (white arrow: previously mastoidectomy state on the right side, black arrow: new bone formation in epitympanum on the left side, arrowhead: soft tissue density in antrum on the left side) (A). A coronal image demonstrates severe new bone formation around the malleus head in the epitympanic area on the left side (arrow: new bone formation) (B).

Numerous reports on middle ear implantation (MEI) using VSB have demonstrated effective auditory benefit together with long-term stability compared to passive reconstruction in patients with mixed or conductive hearing loss. ${ }^{3-}$ ${ }^{9)}$ Here, we report a patient with bilateral mixed hearing loss due to chronic otitis media, who had limitations using conventional hearing aids in the worse hearing ear and was suc- cessfully treated with MEI using the Bell coupler together with middle ear surgery in a single step. We will discuss the options of couplers and surgical tips in performing vibroplasty, as well as the current and future role of MEI in the auditory rehabilitation of patients with mixed hearing loss.

\section{Case Report}

A 54-year-old man visited the hospital due to bilateral hearing impairment and tinnitus. He had previously received canal wall down mastoidectomy with tympanoplasty on the right side about 20 years ago due to chronic otitis media. Widened external auditory canal and tympanized drum was seen on the right side while attic destruction and retraction of drum were identified on the left side (Fig. 1). Pure tone audiogram showed mixed hearing loss on both sides with air-conduction pure tone average of $60 \mathrm{~dB} \mathrm{HL}$ on the right side and $76 \mathrm{~dB}$ HL on the left side (Fig. 1). The speech discrimination score was $88 \%$ on both sides. On temporal bone $\mathrm{CT}$, the mastoid bone was sclerotic with mastoid air cells filled with soft tissue density, and there was also severe new bone formation around the malleus head in the epitympanic area on the left side (Fig. 2). He had tried to use a conventional hearing aid on the right side but failed to attain sufficient auditory gain. On the left side, a hearing aid could not be worn 
regularly because of irritation of the external auditory canal skin. The patient was fitted with hearing aids bilaterally for 2 months; however, there was only minimal improvement of the abbreviated profile of hearing aid benefit (APHAB) score from 79 to 71 and the hearing aid on the left side induced severe itching forbidding its continued use. The overall patient satisfaction was low. After consulting with the patient, we planned canal wall up mastoidectomy and tympanoplasty together with MEI in a single stage on the left ear which was the worse hearing ear.

During the operation, the retracted drum in the attic and
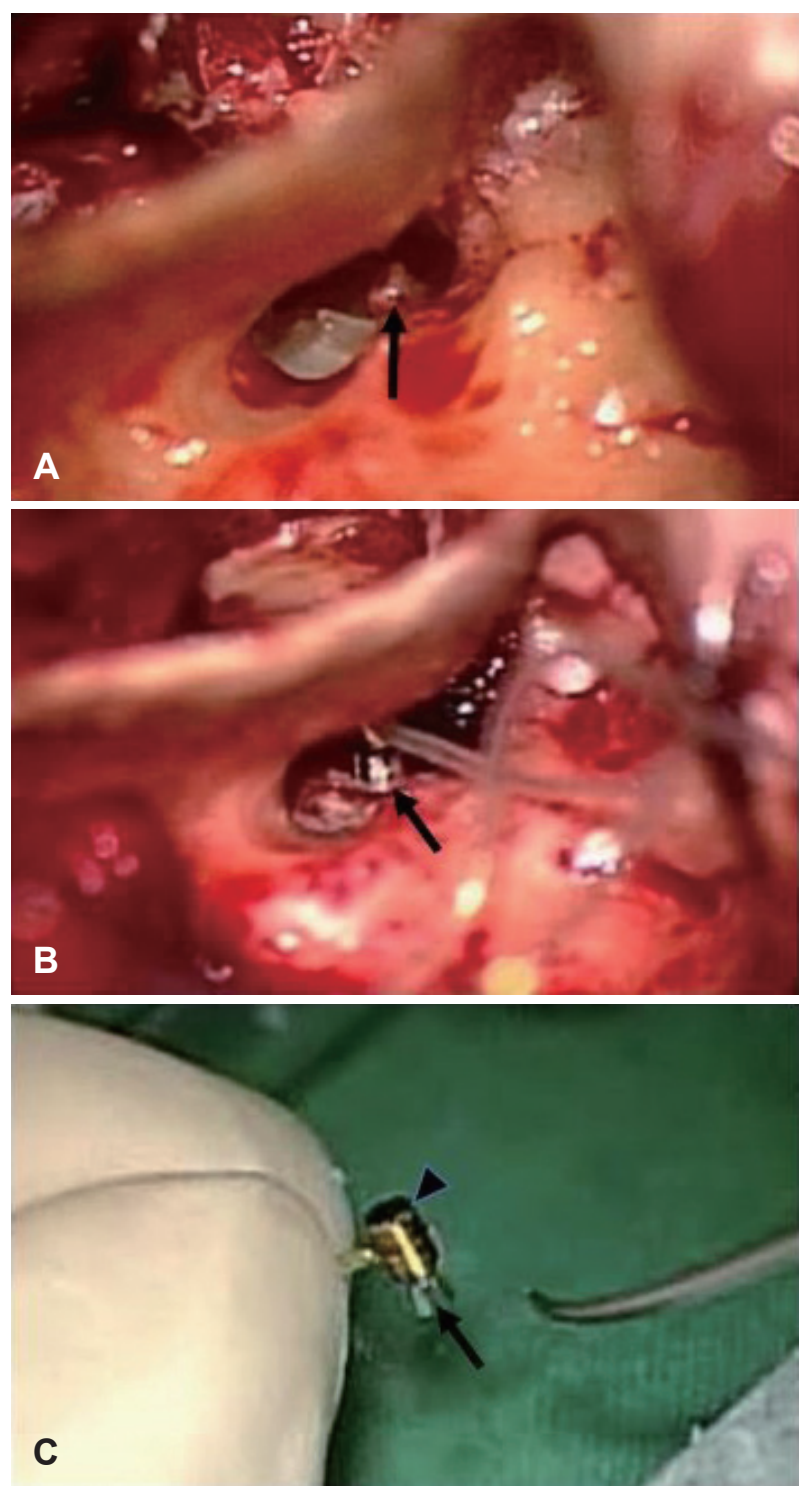

Fig. 3. Operative views through posterior tympanotomy. Stapes was relatively intact with good mobility (arrow: stapes) (A). Bell coupler attached to the FMT was placed over the stapes head (arrow: Bell coupler) (B). FMT was attached to the Bell coupler (arrow: Bell coupler, arrowhead: FMT) (C). FMT: floating mass transducer. posterior tympanic area was carefully elevated. Long process of incus was nearly completely eroded state and the remnant lenticular process of incus was removed. The suprastructure of stapes was present and mobile (Fig. 3). After performing mastoidectomy, remnant incus and malleus head were removed following drilling of the new bone formed in the epitympanum. The FMT of VSB Model 502 (MED-EL) was attached to the Bell coupler and placed over the stapes head through the posterior tympanotomy (Fig. 3). A piece of full-thickness tragal cartilage was placed over the FMT, and the drum was grafted with tragal perichondrium after reconstruction of attic with another piece of cartilage.

The VSB was switched-on 6 weeks after surgery. The unaided air-conduction pure tone average improved from 76 $\mathrm{dB}$ HL to $50 \mathrm{~dB}$ HL due to closure of air-bone gap (Fig. 4). The VSB-aided average threshold improved to $33 \mathrm{~dB}$ HL with significant improvement of thresholds at 2 and $4 \mathrm{kHz}$ (Fig. 4). The speech discrimination score showed improvement from $88 \%$ to $92 \%$. Eight months after surgery, unaided hearing improved to $40 \mathrm{~dB}$ HL and aided thresholds reached 26 dB HL (Fig. 4). The drum was well healed state (Fig. 4). Tinnitus in the left ear disappeared and APHAB global score improved from 79 to 17 . The patient is satisfied with the results and is using MEI on the left side and a conventional receiver in the canal type of hearing aid on the right side for binaural hearing.

\section{Discussion}

One of the main advantages of VSB in treating mixed or conductive hearing loss is that it can provide vibratory stimulation bypassing the external auditory canal and the damaged ossicular chain, often allowing the overclosure of airbone gap especially at $1-4 \mathrm{kHz} .^{10-12)}$ Another advantage would be being able to be free of an ear level external device which can be a hindrance in radical cavities or auditory canals with chronic infections. ${ }^{11)}$ In patients with mixed or conductive hearing loss, the FMT of VSB may be connected to the round window, oval window, remnants of the ossicular chain depending on the condition of the middle ear either directly or using various couplers to improve the feasibility of surgical procedures and also the functional outcome. , $^{1,6-8,12-14)}$ When there is an intact and mobile stapes suprastructure such as in the present case, either a Bell coupler or a Clip coupler can be applied. ${ }^{12)}$ A Bell coupler is easier to apply on the stapes head but has the risk of prosthesis tilting when the weight of the 
FMT is added. A Clip coupler with an additional force coupling to the stapes head may provide better sound transmission and stability, but has limited use in cases of atrophic stapes head or when the stapes is in a narrow relation to the promontory. ${ }^{12,13)}$ In this case report, the Bell coupler was chosen because of limited space between the stapes head and the promontory. Round window vibroplasty is indicated when there is a missing or fixed ossicular chain prohibiting placement of FMT on the oval window or the ossicles. A round window coupler helps reduce the drilling of the round window niche leading to lower risk of noise or membrane trauma. ${ }^{12)}$ The hearing gain in stapes and round window vibro-
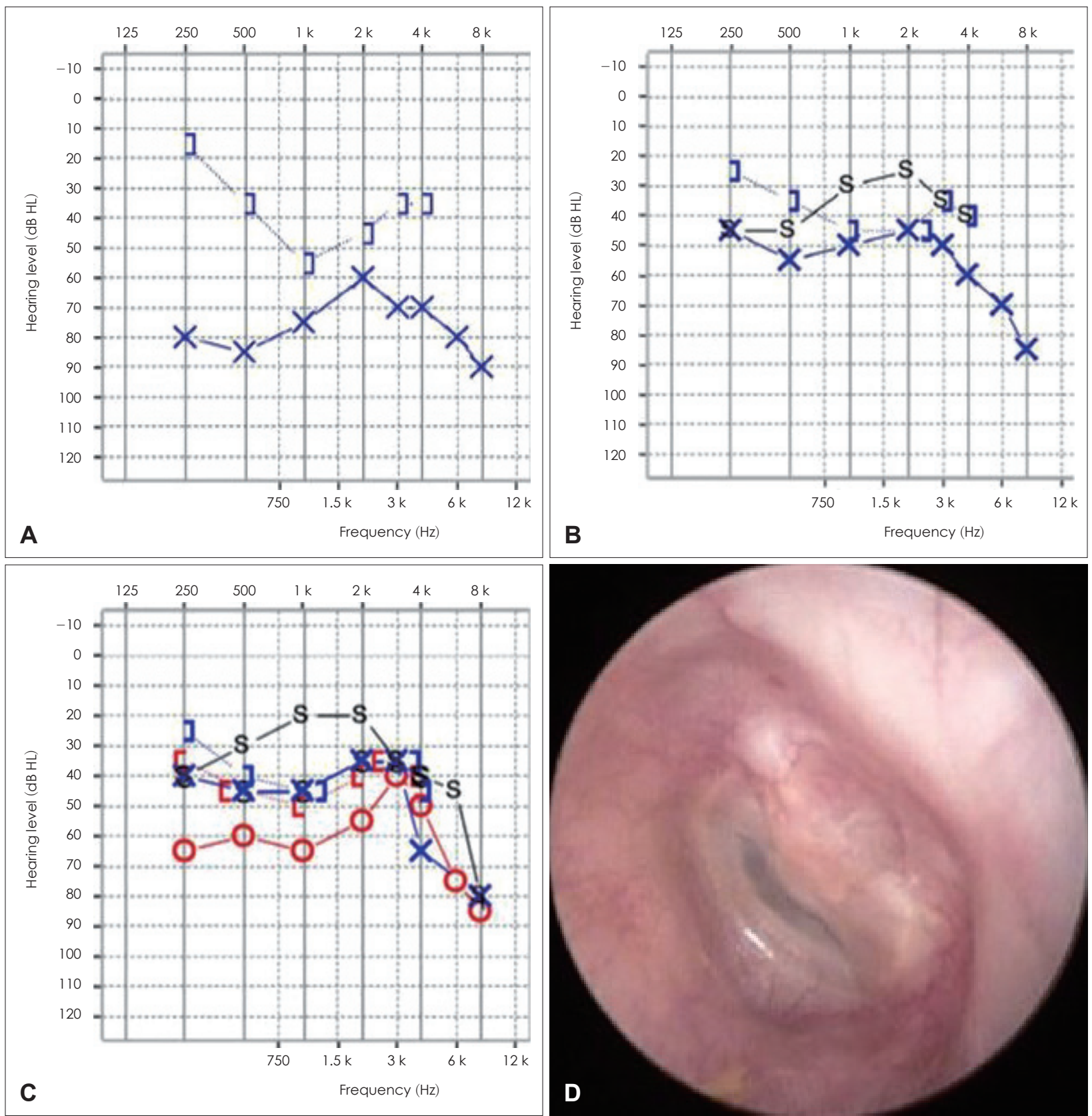

Fig. 4. Changes of pure tone audiometry and postoperative endoscopic view of left tympanic membrane. The preoperative pure tone audiogram. Mixed hearing loss was seen on the left side with unaided air-conduction pure tone average of $72 \mathrm{~dB} H L(A)$. Pure tone audiogram six weeks after surgery following switch-on of VSB. The unaided air-conduction pure tone average improved from $72 \mathrm{~dB}$ $\mathrm{HL}$ to $50 \mathrm{~dB} \mathrm{HL}$ due to closure of air-bone gap. VSB-aided average threshold improved to $33 \mathrm{~dB} H \mathrm{HL}$ with significant improvement of thresholds at 2 and $4 \mathrm{kHz}(\mathrm{B})$. Pure tone audiogram eight months after surgery. The unaided hearing improved to $40 \mathrm{~dB} H \mathrm{HL}$ and aided thresholds reached $26 \mathrm{~dB} \mathrm{HL}$ (C). Postoperative endoscopic view of left tympanic membrane. The drum was well healed state (D). O: right air-conduction unmasked, X: left air-conduction unmasked, S: sound field, [: right bone-conduction masked, ]: left bone-conduction masked, VSB: Vibrant Soundbridge. 
plasties was comparable ranging from $30 \mathrm{~dB}$ to $50 \mathrm{~dB}$ in previous studies, but stapes vibroplasty is technically easier with less surgical risk of damaging the inner ear and enables more efficient and stable coupling compared to round window vibroplasty, resulting in better gain in the high frequencies. ${ }^{8,11)}$ In addition, the FMT in stapes vibroplasty may work as a passive prosthesis and provide hearing gain even in unaided conditions as in this case report. Therefore, it is recommended that stapes vibroplasty should be considered first whenever permitted by the middle ear condition. When performing stapes vibroplasty, it is better to use a full-thickness cartilage for long-term stability., ${ }^{6,12)}$

With the accumulation of clinical data on effectiveness and safety of VSB as well as the advent of technical improvement regarding the VSB device and various couplers, the indications of MEI are expanding and MEI may be considered as an initial treatment modality in patients with mixed hearing loss who are not expected to benefit from conventional modalities or those who cannot wear hearing aids due to problems of the auditory canal. ${ }^{8,10-12)}$ However, there are not many previous reports in the literature on cases of mixed hearing loss in which MEI was performed together with a middle ear surgery in a single step. ${ }^{8)}$ In the present case, the patient had failed effective auditory benefit following middle ear surgery on one side, and a hearing aid could not be worn on the contralateral side due to auditory canal skin problems despite bilateral mixed hearing loss. After given full information on the advantages and disadvantages of VSB and the surgical procedures, the patient did not want multiple surgeries and preferred to receive middle ear surgery for the cholesteatoma and VSB implantation in a single step. The surgical risks, limitation in the use of MRI, and the possibility of revision surgery have to be considered in performing middle ear implantation but these disadvantages may be reduced in the future with the development of new devices such as VSB model 503 (MED-EL) which is MRI safe up to 1.5 Tesla., ${ }^{9,15}$

This report demonstrates the effectiveness of stapes vibroplasty for both passive reconstruction and active middle ear stimulation using VSB in a patient with bilateral mixed hearing loss who could not benefit from conventional hearing aids. In performing vibroplasty, good coupling using appropriate couplers and stabilization of the FMT are very important for maximal hearing gain. More future studies are expect- ed to broaden the candidacy of MEI in mixed and conductive hearing loss patients.

\section{Acknowledgments}

This research was supported by the Basic Science Research Program (2015R1A1A1A05001472) of the National Research Foundation (NRF) funded by the Ministry of Science, ICT \& Future Planning.

\section{REFERENCES}

1) Colletti V, Soli SD, Carner M, Colletti L. Treatment of mixed hearing losses via implantation of a vibratory transducer on the round window. Int J Audiol 2006;45(10):600-8.

2) Ernst A, Todt I, Wagner J. Safety and effectiveness of the Vibrant Soundbridge in treating conductive and mixed hearing loss: a systematic review. Laryngoscope 2016;126(6):1451-7.

3) Baumgartner WD, Böheim K, Hagen R, Müller J, Lenarz T, Reiss S, et al. The Vibrant Soundbridge for conductive and mixed hearing losses: European multicenter study results. Adv Otorhinolaryngol 2010;69:38-50.

4) Mlynski R, Mueller J, Hagen R. Surgical approaches to position the Vibrant Soundbridge in conductive and mixed hearing loss. Oper Tech Otolayngol Head Neck Surg 2010;21(4):272-7.

5) Beltrame AM, Todt I, Sprinzl G, Profant M, Schwab B. Consensus statement on round window vibroplasty. Ann Otol Rhinol Laryngol 2014;123(10):734-40.

6) Luers JC, Hüttenbrink KB, Zahnert T, Bornitz M, Beutner D. Vibroplasty for mixed and conductive hearing loss. Otol Neurotol 2013;34(6):1005-12.

7) Vyskocil E, Riss D, Honeder C, Arnoldner C, Hamzavi JS, Baumgartner $\mathrm{WD}$, et al. Vibroplasty in mixed and conductive hearing loss: comparison of different coupling methods. Laryngoscope 2014;124(6):1436-43.

8) Lee JM, Jung J, Moon IS, Kim SH, Choi JY. Benefits of active middle ear implants in mixed hearing loss: stapes versus round window. Laryngoscope 2017;127(6):1435-41.

9) Schraven SP, Gromann W, Rak K, Shehata-Dieler W, Hagen R, Mlynski R. Long-term stability of the active middle-ear implant with floatingmass transducer technology: a single-center study. Otol Neurotol 2016;37(3):252-66.

10) Jung J, Roh KJ, Moon IS, Kim SH, Hwang KR, Lee JM, et al. Audiologic limitations of Vibrant Soundbridge device: is the contralateral hearing aid fitting indispensable? Laryngoscope 2016;126(9):2116-23.

11) Lüers JC, Hüttenbrink KB. Vibrant Soundbridge rehabilitation of conductive and mixed hearing loss. Otolaryngol Clin North Am 2014;47(6):915-26.

12) Zahnert T, Löwenheim H, Beutner D, Hagen R, Ernst A, Pau HW, et al. Multicenter clinical trial of vibroplasty couplers to treat mixed/ conductive hearing loss: first results. Audiol Neurootol 2016;21(4): 212-22.

13) Hüttenbrink KB, Beutner D, Bornitz M, Luers JC, Zahnert T. Clip vibroplasty: experimental evaluation and first clinical results. Otol Neurotol 2011;32(4):650-3.

14) Mancheño M, Aristegui M, Sañudo JR. Round and oval window anatomic variability: its implication for the vibroplasty technique. Otol Neurotol 2017;38(5):e50-e7.

15) Renninger D, Ernst A, Todt I. MRI scanning in patients implanted with a round window or stapes coupled floating mass transducer of the Vibrant Soundbridge. Acta Otolaryngol 2016;136(3):241-4. 